\title{
Improving Municipal Urban Design Decision-Making by Using Digital Tools
}

UMUT TOKER

Umut Toker, Ph.D. is assistant professor at Cal Poly's City and

Regional Planning Department.

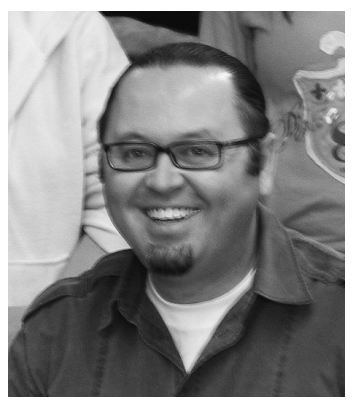

Figure 1

The context: the terrain, streets and buildings in basic prosmatic format, generated using GIS data.
Since joining the CRP Department in 2005, assistant professor, Umut Toker has been boosting the department's capabilities in computer applications for planning, particularly 3-D digital modeling. He recently developed a 3-D model of downtown San Luis Obispowhich will eventually include the whole town--and is working on models for Arroyo Grande and Atascadero. These models, funded by the City of San Luis Obispo and SLOCOG, are powerful tools for development control, and will facilitate community participation.

In Fall 2006, the City and Regional Planning Department started working with the City of San Luis Obispo to create a digital three-dimensional model of Downtown San Luis Obispo. In a nine-month time frame a computer-based three-dimensional model was developed. The project consisted of three-dimensionally modeling an eighteen-block area of downtown San Luis Obispo in detail, as well as the remaining portions of the city in basic form. The objective was to develop a decision support tool that enables city staff, commissions, and the public to be able to visualize developer or municipal submitted proposals. This is especially important today, since the city is considering revising its height limits for downtown--an issue that has opened substantial debate. The project was composed of three main tasks, although the tasks were carried out somewhat simultaneously as the project developed.

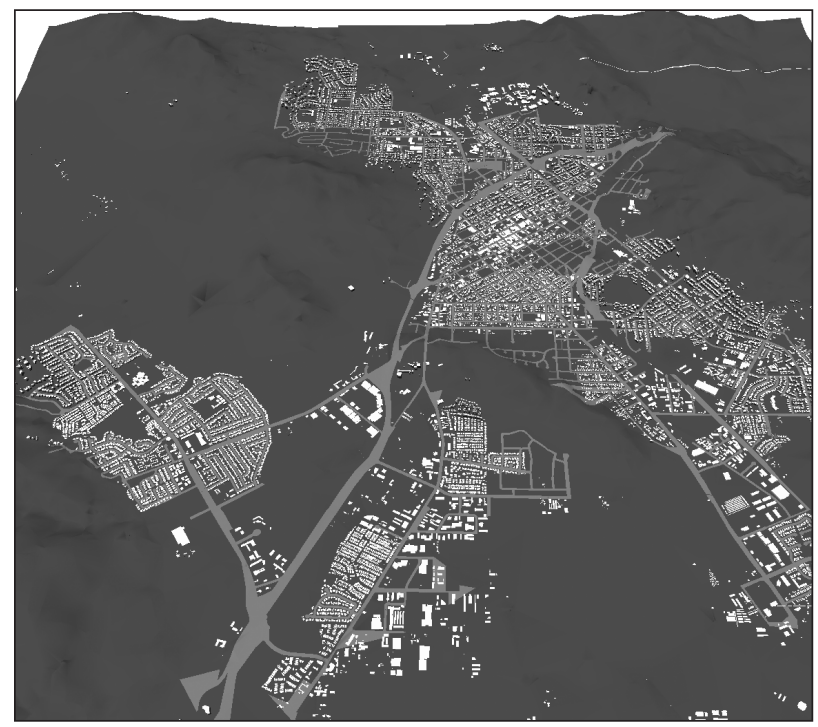

Task 1 entailed development of the context for the 18-block project core area. Using the city's GIS data and aerial photographs, the terrain, streets, and the existing buildings were modeled. In this process, raster terrain data was converted to TIN files, which in turn were made readable by CAD software, in this case, AutoCAD and SketchUp. The street structure of the city was overlaid on the 3D digital terrain. Finally, using the City of San Luis Obispo's building footprint data and its elevation and height attributes, all buildings in the database were extruded to the provided height and elevated to the provided elevation (Figure 1).

The most complex task, Task 2 was the construction of a detailed 3-D digital model of the 18-block project core area. For this, high-resolution, up-to-date aerial photographs and roofline and curbline data of the project area were provided by the City of San Luis Obispo. Roofline and curbline data were originally in 3-D polyline format, which had to be processed to develop "closed" polylines, hence surfaces in SketchUp software. Once this process was complete, blocks, streets and buildings were created in basic, no-detail prismatic format. At this point, façade photographs of all buildings in the project area were taken. These photographs were mapped onto prismatic building models, which 
made "carving" of façade details possible. At the end of this process, the 18-block project core area was modeled with all buildings and front façade details (Figure 2).

The final task, Task 3 was composed of building more details, additional elements into the project area, as well as the integration of the detailed 18-block project core and its context model. Using the high-resolution aerial photographs and façade photographs, trees, street furniture, parking meters, and further details of open spaces were built into the model. Finally, silhouettes of people were added to enhance the feeling of scale, and the two models (the detailed core model and the context model) were integrated (Figure 3).

The City of San Luis Obispo will start requiring project proposals to include a three-dimensional computer model, and will analyze proposals visually. The tool will not only provide accurate analysis, but also create significant potential for community input in the city's development issues, such

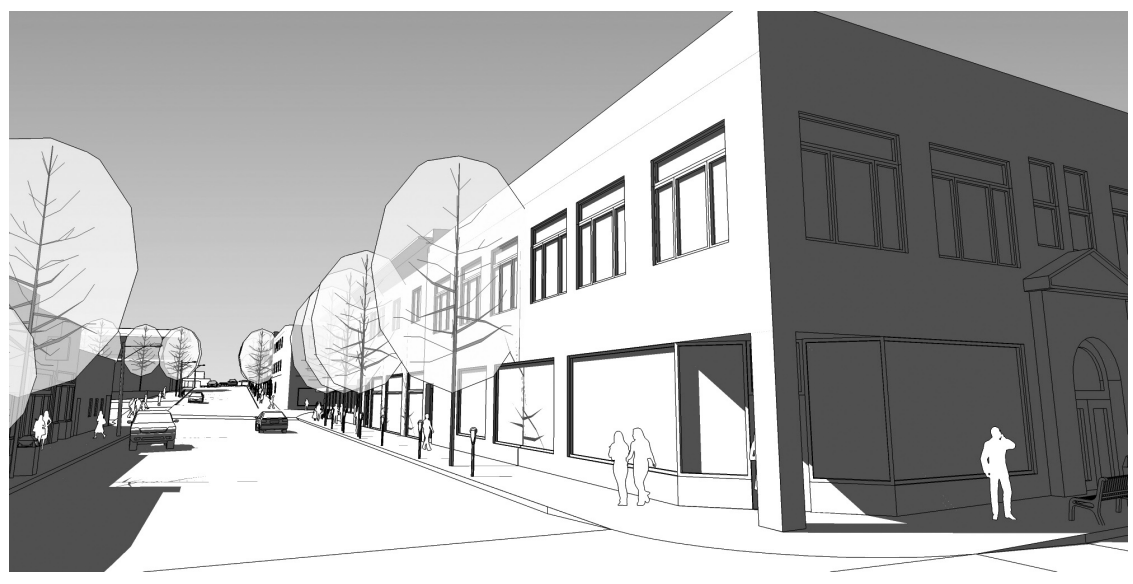

Figure 2

Buildings and front facade details.

This process also inspired other communities on the central coast. In Fall 2007, the CRP department was contacted for another modeling project--this time by SLOCOG--for its Community 2050 process. While the San Luis Obispo project targeted developing a detailed model of the existing conditions, SLOCOG's aim was to focus on the present and future of two urban corridors-Arroyo Grande's Grand Avenue and Atascadero's El Camino Real. Still under progress, this project will model these two urban corridors, depicting their existing state, and their potential future streetscapes in 2020, 2035, and 2050. All potential future streetscape projections and assumptions are completely provided by the Community Development Departments of these two cities, allowing the project supervisor to focus on 3-D modeling quality.

Use of this technology creates a new level of transparency in the decision making process, as shared file data and distributed images can be made available for multiple stakeholders. Both the City of San

Figure 3

Project area located in the context model.

Luis Obispo and SLOCOG will be using these models to better inform stakeholders of how urban design decisions may affect their public space. Therefore, these and future similar projects will be of critical importance for communities that would like to make decisions through community involvement. The CRP Department wishes to further its efforts to develop cutting-edge methods of technology use and to support other communities with similar projects.

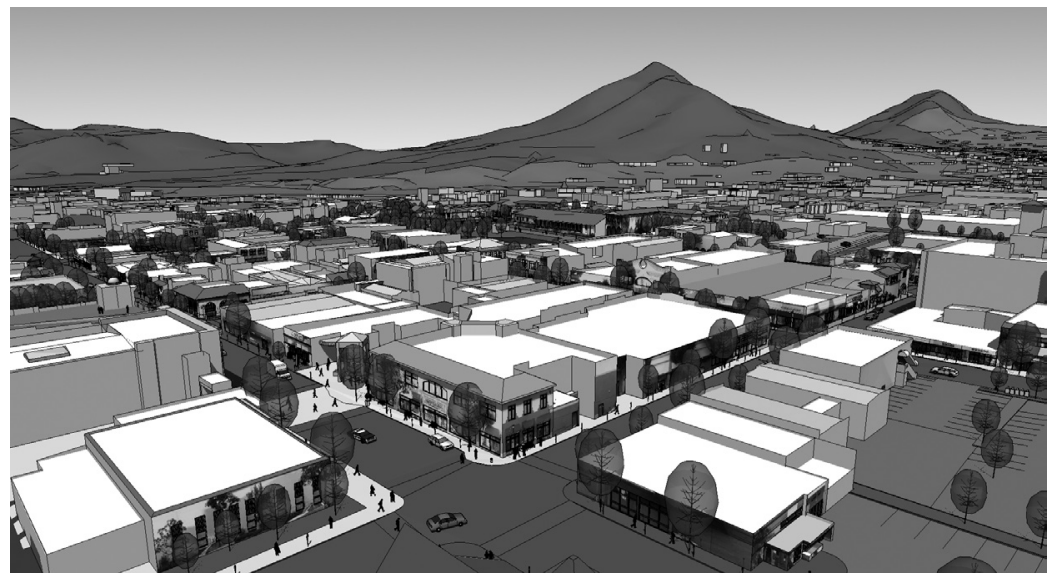

